\title{
Smart Home using Kinco PLC
}

\author{
Moe Mon Myint ${ }^{1}$, Phyo Thu Aung ${ }^{2}$, Wai Phyo ${ }^{2}$ \\ ${ }^{1}$ Professor, ${ }^{2}$ Researcher \\ Department of Electronic Engineering, Pyay Technological University, Pyay, Myanmar
}

\begin{abstract}
This paper describes about smart home using Kinco PLC programming. Nowadays, smart homes are popular in everywhere. A smart home can provide its home owner with comfort, security, energy efficiency, and convenience at all times, regardless of whether anyone is home. In this report, smart home is designed to control multiple systems by using PLC. Gate door control is combined with radio frequency remote control and Main door security is designed with access control which can work with RFID card and password. There is also another security solution, CCTV and fire alarm system for monitoring and firefighting. For the lighting control, it can automatically ON/OFF with PLC programming. Moreover, garage door control system is added. User friendly operation and less error solution are designed for home automation.
\end{abstract}

Keywords: PLC, Kinco, Gate door control, RFID, CCTV

\section{INTRODUCTION}

Home automation is building automation for home called a smart home. A home automation system will control lighting, temperature inside the house, entertainment systems, and electronic appliances. It also includes home security such as access control and alarm systems. In this report, PLC (Kinco) is used as the core and control the home's security systems and other appliances. Most of the smart home uses microcontroller but in this research what innovated is the prototype of smart home using PLC which is the chosen major.

To keep the house from harms, the information of what is happening in the house has become essential. This research does fulfill this need by monitoring the house and by notifying the user via alarms, buzzer and monitor. One more thing, this sample assists the user by opening and closing the gate door with remote control and automatic garage control.

\subsection{Operation Summary}

From remote controller, the gate door open/close and the lighting on/off of the fence can be controlled. As soon as the gate door opens, the CCTV 1 starts working and showing the image of the gate to the monitor. When the gate door closes, CCTV 1stops working. The garage door can be opened by passing the car through the photoelectric sensor that will close automatically 30 seconds later.

As the main door bell is rung, the CCTV 2 starts working like CCTV 1 and stops 15 seconds later. When the right password is typed, or the recognized RFID card is shown, the solenoid lock will release. Two photoelectric sensors are used in the main house lighting control system and using the counting program the lights will switch on and off. For firefighting, flame detector and smoke detector are used as inputs and buzzer and alarm are used as outputs. Fig. 1.1 shows the overall block diagram and the blocks associated with the gate door operation system. 


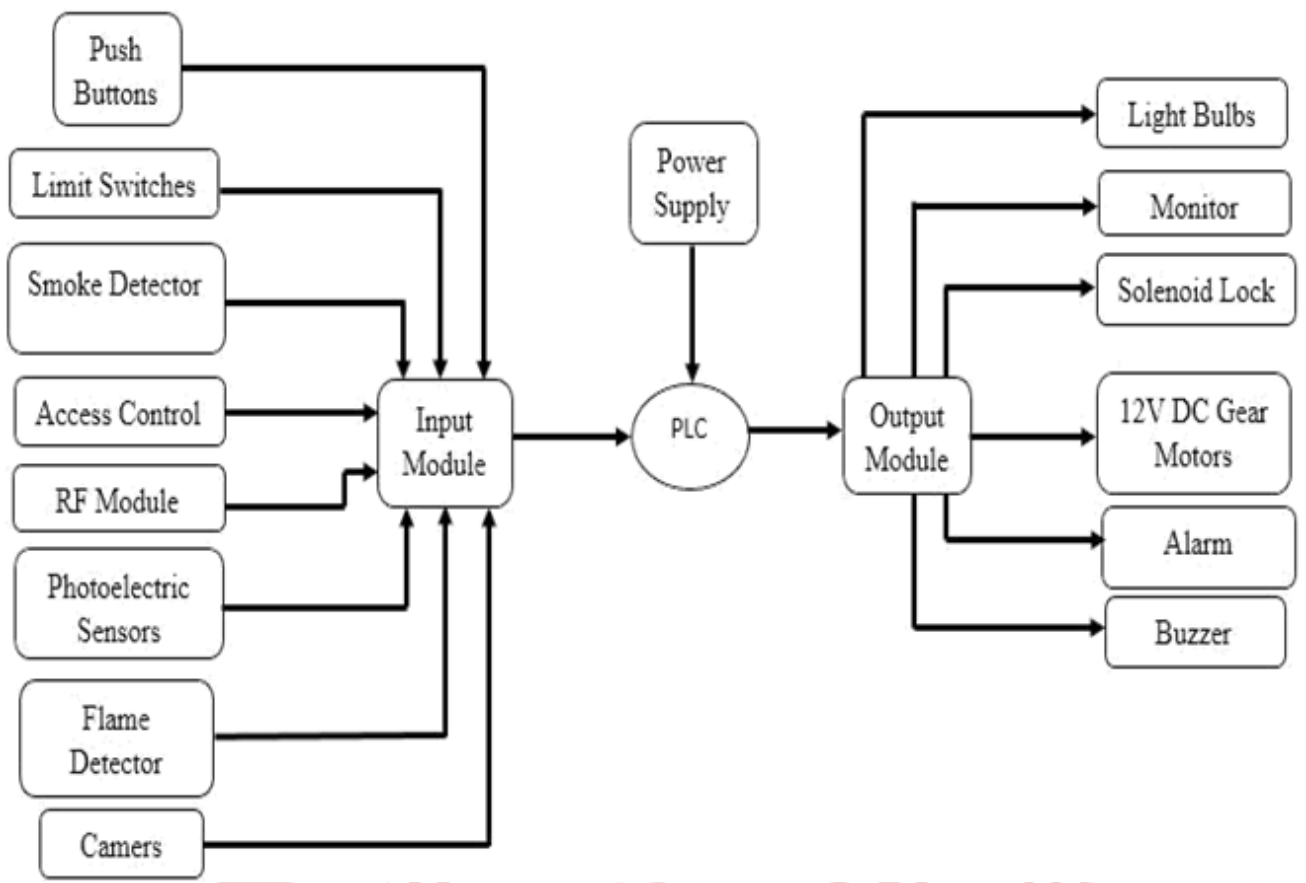

Figure1. Overall Block Diagram and the Blocks of the Chosen System

\subsection{System Requirements}

This system contains the following hardware and software requirements. The hardware requirements are:

$>$ Kinco K5 PLC

$>$ Photoelectric sensor

$>$ smoke detector

$>$ Flame detector

$>$ Buzzer

$>$ Alarm

$>$ Push button

$>$ Relays

$>2$ car rare view cameras

$>1$ monitor

$>$ CEN-102 Access Control

$>$ Power Supply 12V DC, 24V DC

$>$ Solenoid Lock

$>$ RFID or smart card

$>$ The software requirements are:

$>\mathrm{RS}-232$ serial connector

$>$ KincoBuilder V3.0.0.0. En Programming software

\section{SYSTEM PORTIONS}

This section is divided into six main parts. They are gate door access control system, main door access control system, CCTV installation system, lighting control system, fire fighting control system and garage control system. Firstly, RF module is used to open and close the gate door access control system. The CEN-102 access control and solenoid lock are used to open and close the main door access control system. After that, 2 car rare view cameras and 1 monitor are used to install the CCTV system. The smoke detector, flame detector, buzzer and alarm are used for the fire-fighting system. The photoelectric sensor and push button are used for the lighting control system and garage control systems. The next section follows the wiring diagram and system flow charts. And then the test and result are discussed the following sections. The following figures show the block diagram of each portion.

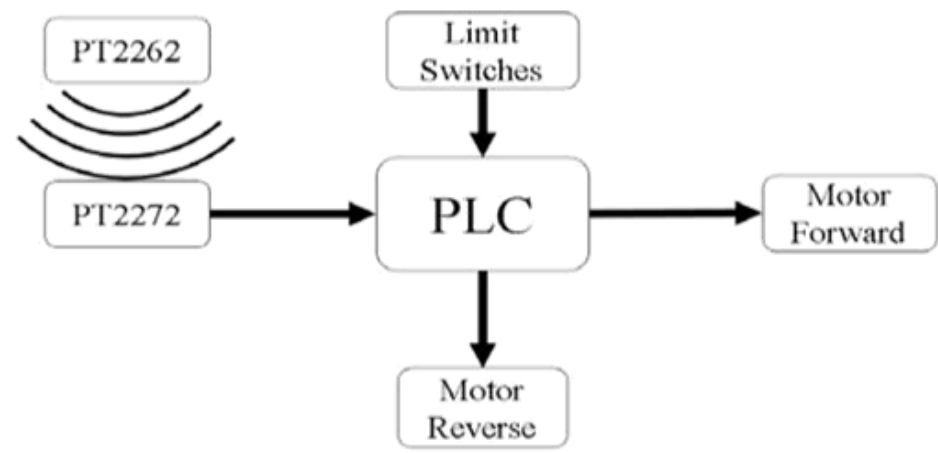

Figure2. Block Diagram of Gate Door Operation System 


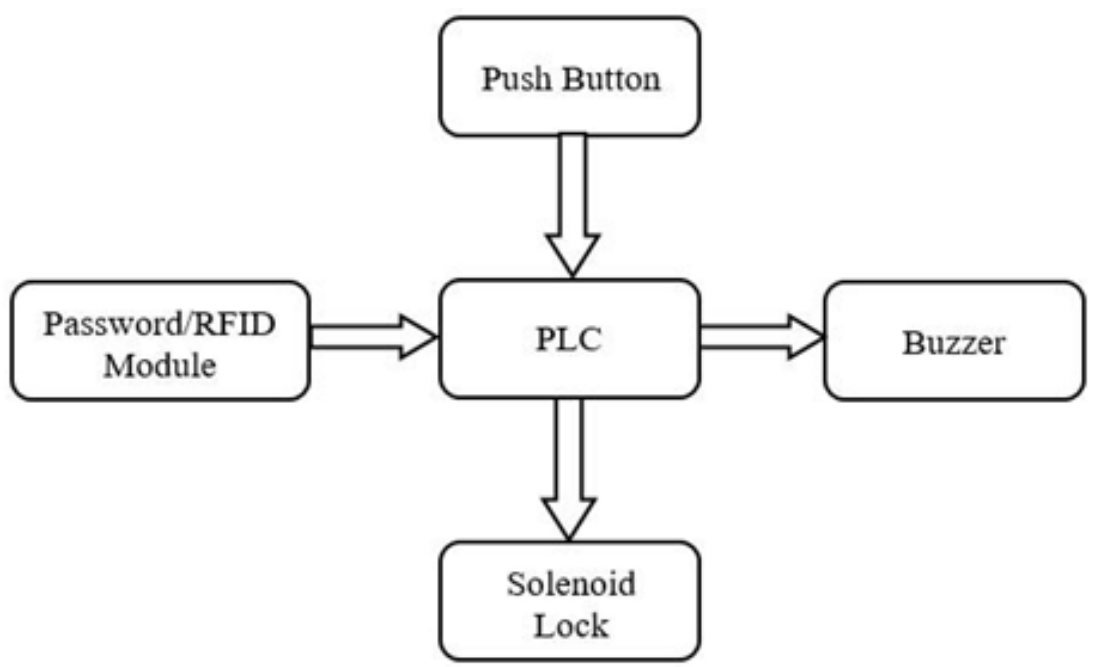

Figure3. Block Diagram of Main Door Operation System

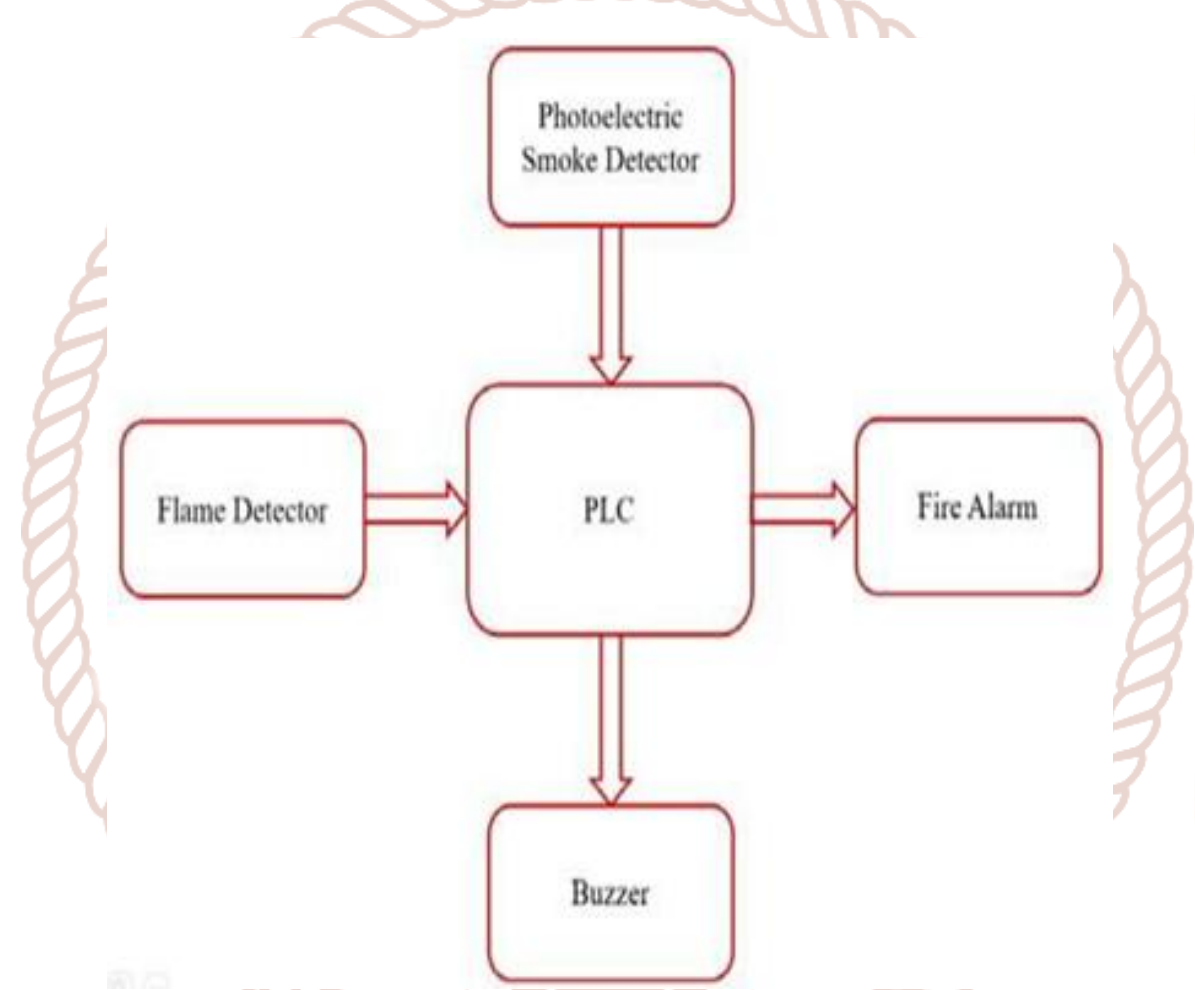

Figure4. Block Diagram of Fire-fighting System

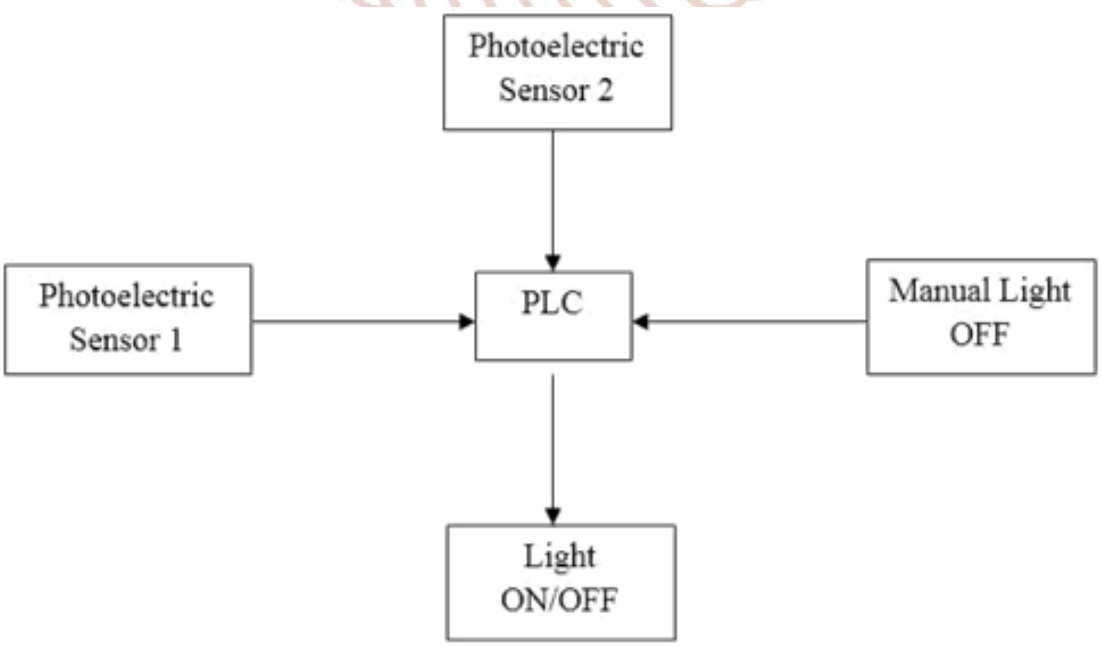

Figure5. Block Diagram of Lighting Control System 


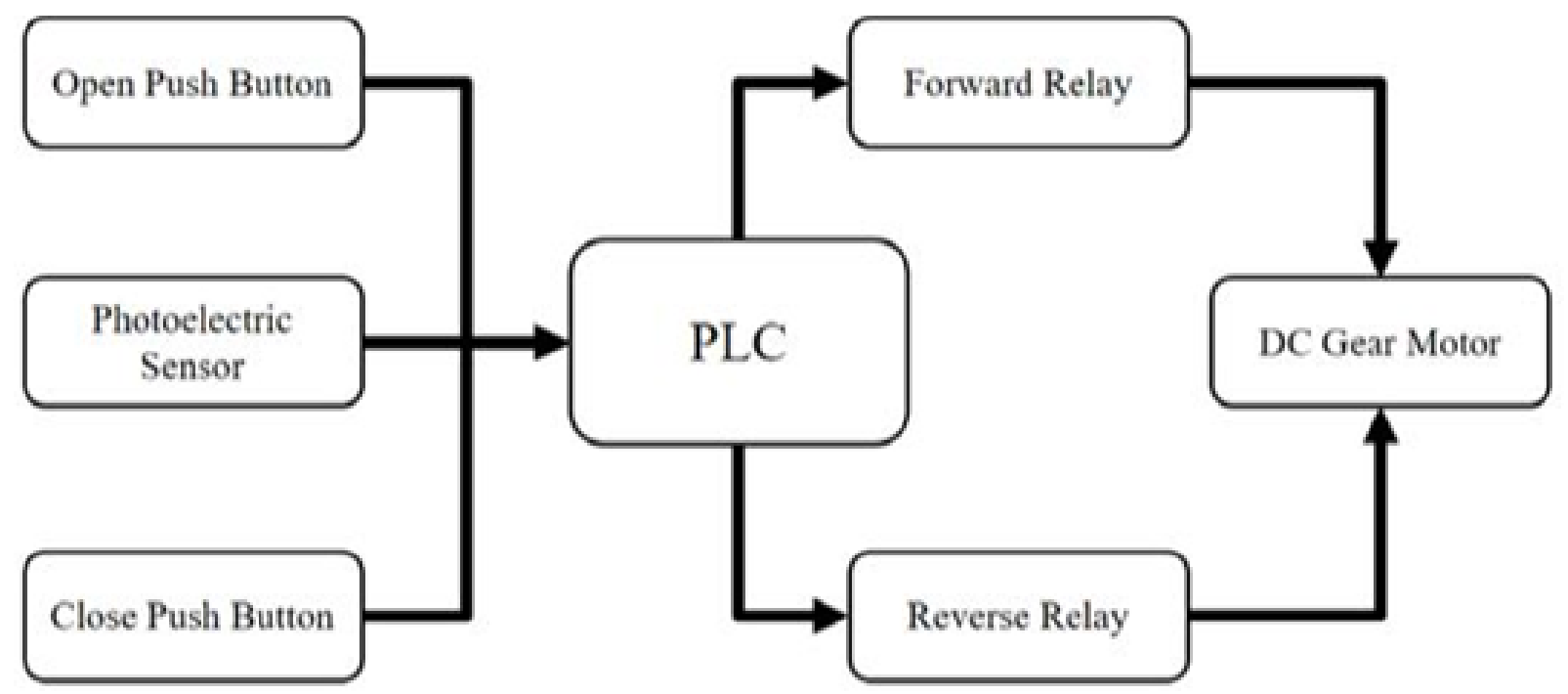

Figure6. Block Diagram of Garage Door System

\subsection{Flow Chart and Control Program of the System}

This section discusses about the flow charts and control program of the system. Before the software implementation, the author needs to draw the flow charts. By doing these, the software implementation is successfully installed. And then the Kinco PLC programs will be constructed using ladder programming. In these programming languages, there are many instructions. Among them, some instructions are used in this system. Then, the author needs to assign the input and output addresses to know the Kinco PLC. The following table shows the input/ output assignment table according to the whole system.

\begin{tabular}{|c|c|c|c|}
\hline $\begin{array}{l}\text { Input } \\
\text { Address }\end{array}$ & Description & $\begin{array}{l}\text { Output } \\
\text { Address }\end{array}$ & Description \\
\hline I0.0 & RF_A De & Q0.0 & Gate_Open $\square$ \\
\hline $\mathrm{I} 0.1$ & RF_B & Q0.1 & Gate_Close \\
\hline $\mathrm{I} 0.2$ & Limit_Switch_12 & $\mathrm{Q} 0.2$ & Lock_ON \\
\hline $\mathrm{I} 0.3$ & MainDoor_ON & $\mathrm{Q} 0.3$ & Alarm_ON \\
\hline I0.4 & Door_Bell & Q0.4 & Lignt_ON \\
\hline $\mathrm{I} 0.5$ & Count_UP & Q0.5 & FireAlarm_ON \\
\hline I0.6 & Count_Down & Q0.6 & $\mathrm{CCTV}_{-} 1$ \\
\hline $\mathrm{I} 0.7$ & Manul_OFF & Q0.7 & CCTV_2 \\
\hline $\mathrm{I} 1.0$ & Alarm_Reser & Q1.0 & StoreDoor_Open \\
\hline I1.1 & Heat_Detect & Q1.1 & StoreDoor_Close \\
\hline $\mathrm{I} 1.2$ & Smoke_Detect & & \\
\hline $\mathrm{I} 1.3$ & Limit_Switch_34 & & \\
\hline $\mathrm{I} 1.4$ & Manual_Close & & \\
\hline $\mathrm{I} 1.5$ & Car_IN & & \\
\hline
\end{tabular}




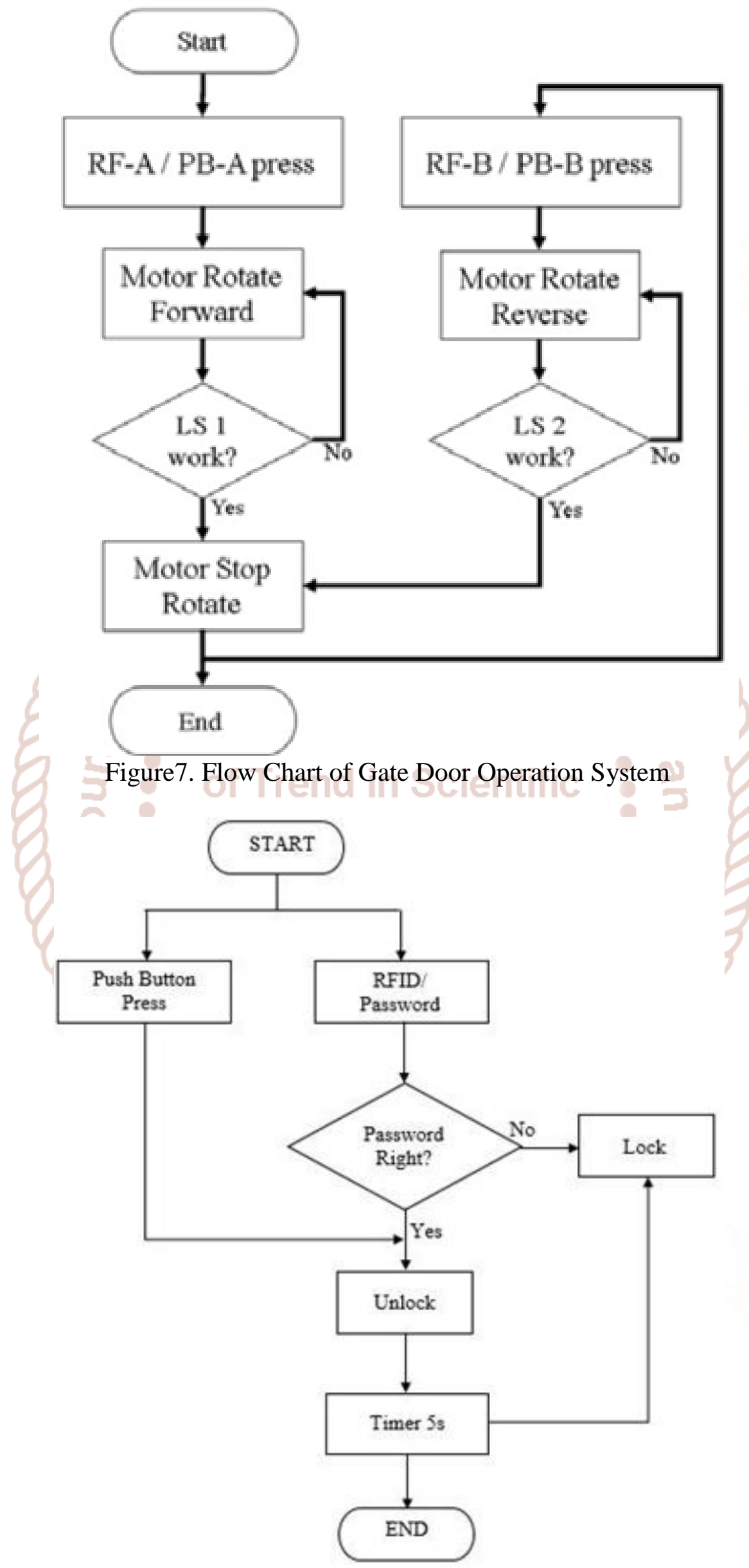

Figure8. Flow Chart of Main Door Operation System 


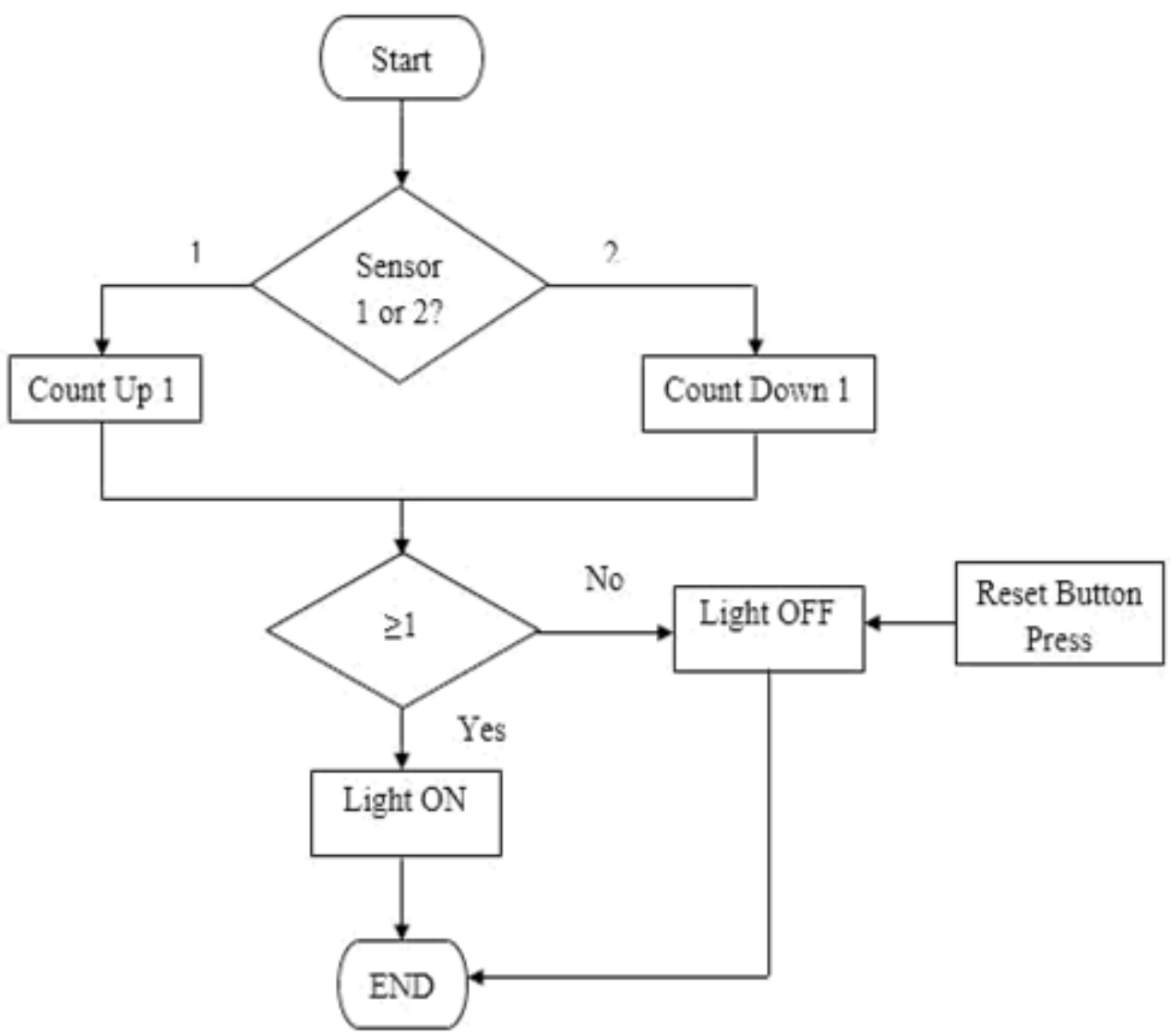

Figure9. Flow Chart of Lighting Control System

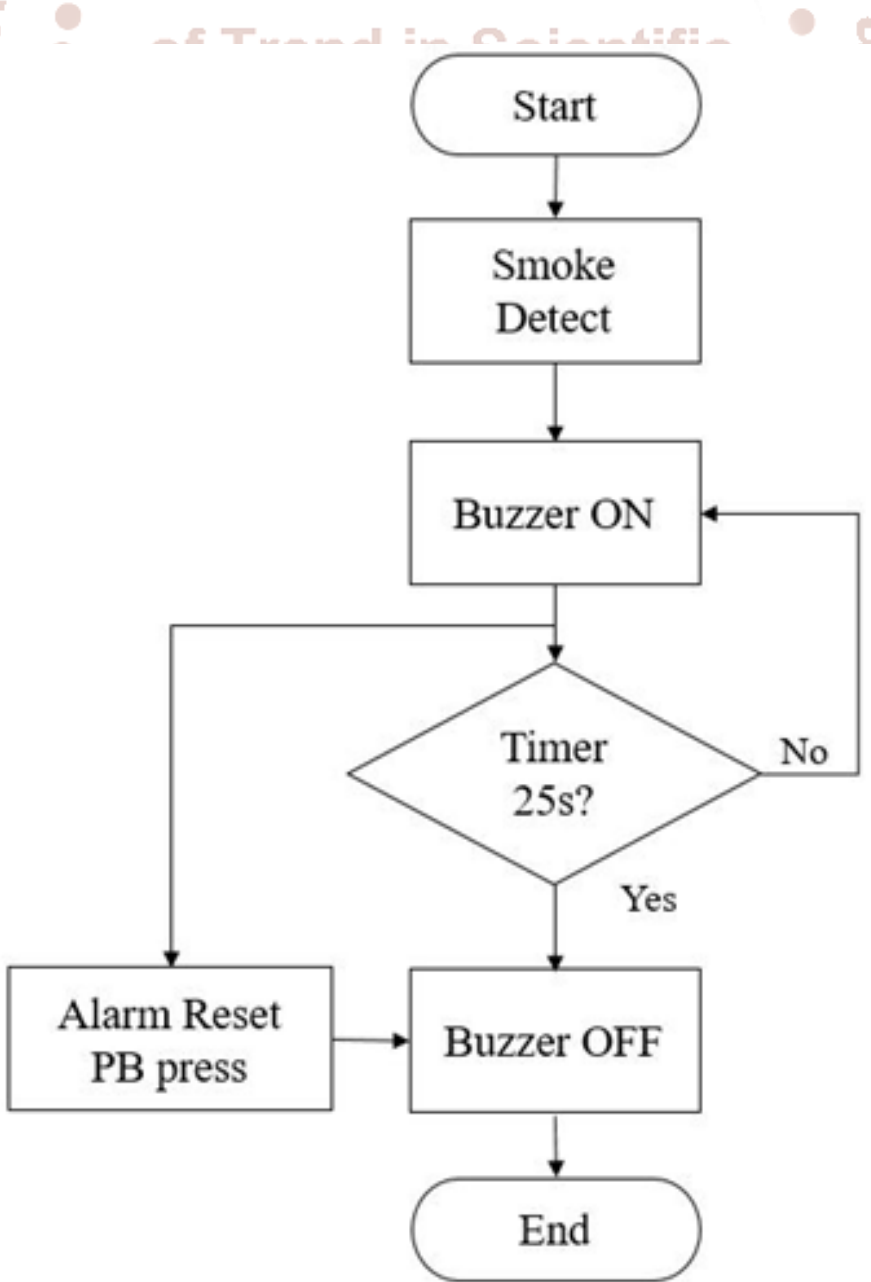

Figure10. Flow Chart of Smoke Detection 


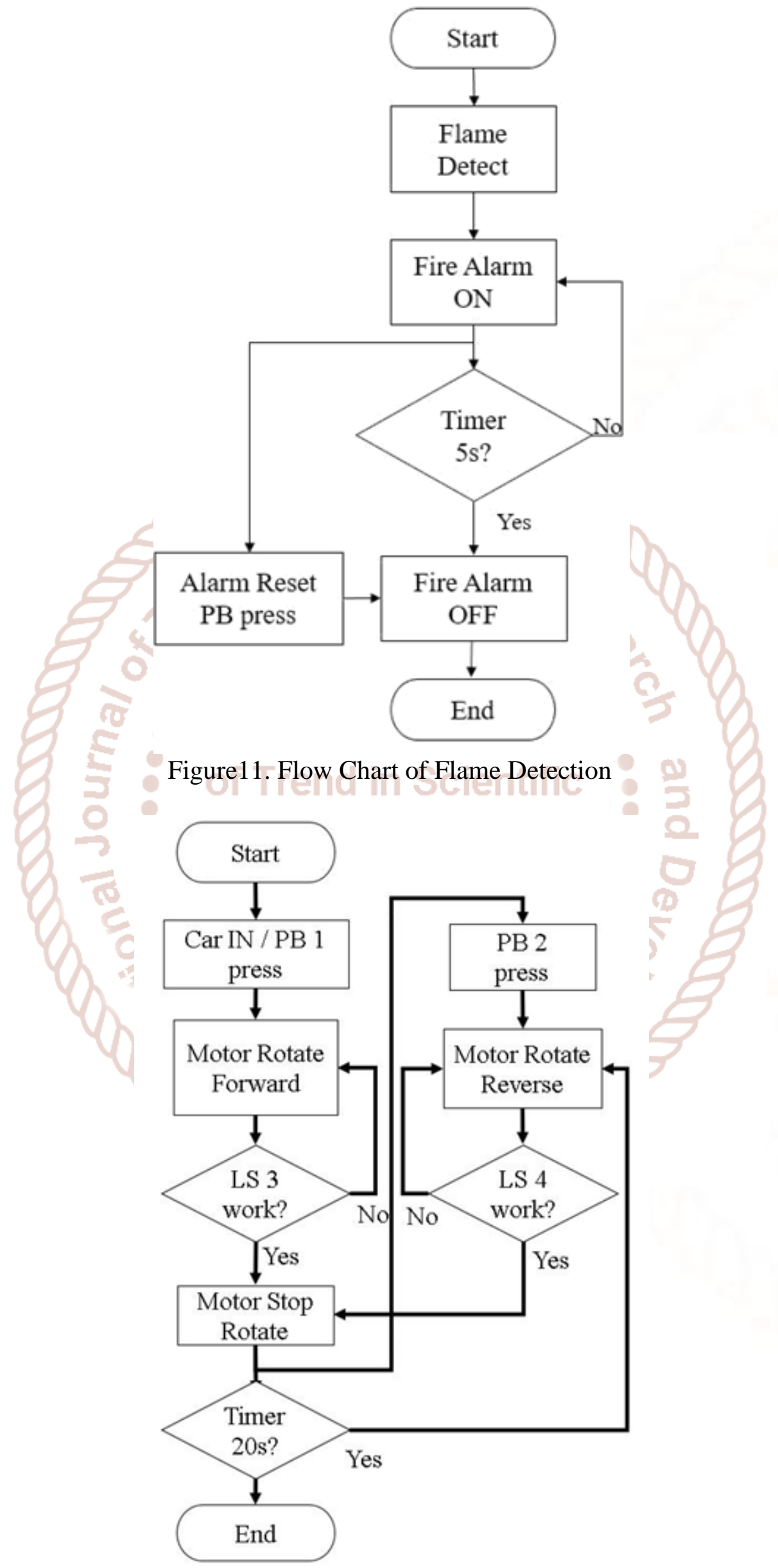

Figure12. Flow Chart of Garage Door Control System 


\section{TEST AND RESULTS}

In the initial state of the system the door is closed, therefore, all the output is in normally open state. When the open button from the remote is pressed, the RF_A becomes close state and the gate will open. When the close button from the remote is pressed, the RF_B becomes close state and the gate will close. In opening state, when the gate door touches the limit switch, the Limit_Switch_12 will become close and the output pulse reaches Gate Close and the opening state is stopped. The closing states also work the same as the above method. The following figures show the initial state of the system and the components used in the system and the respective program.

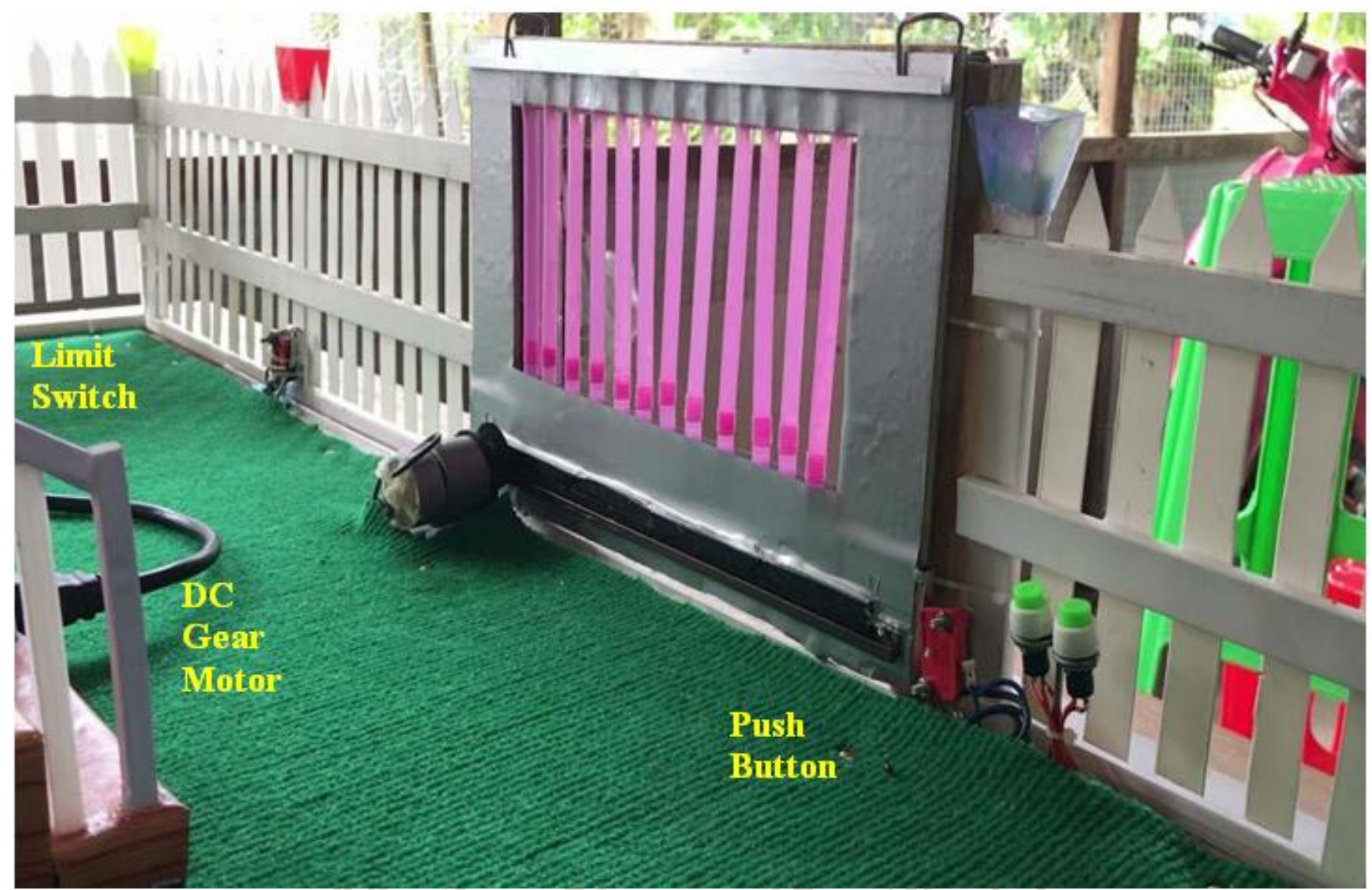

Figure13. Test and Result of Gate Door Operation System

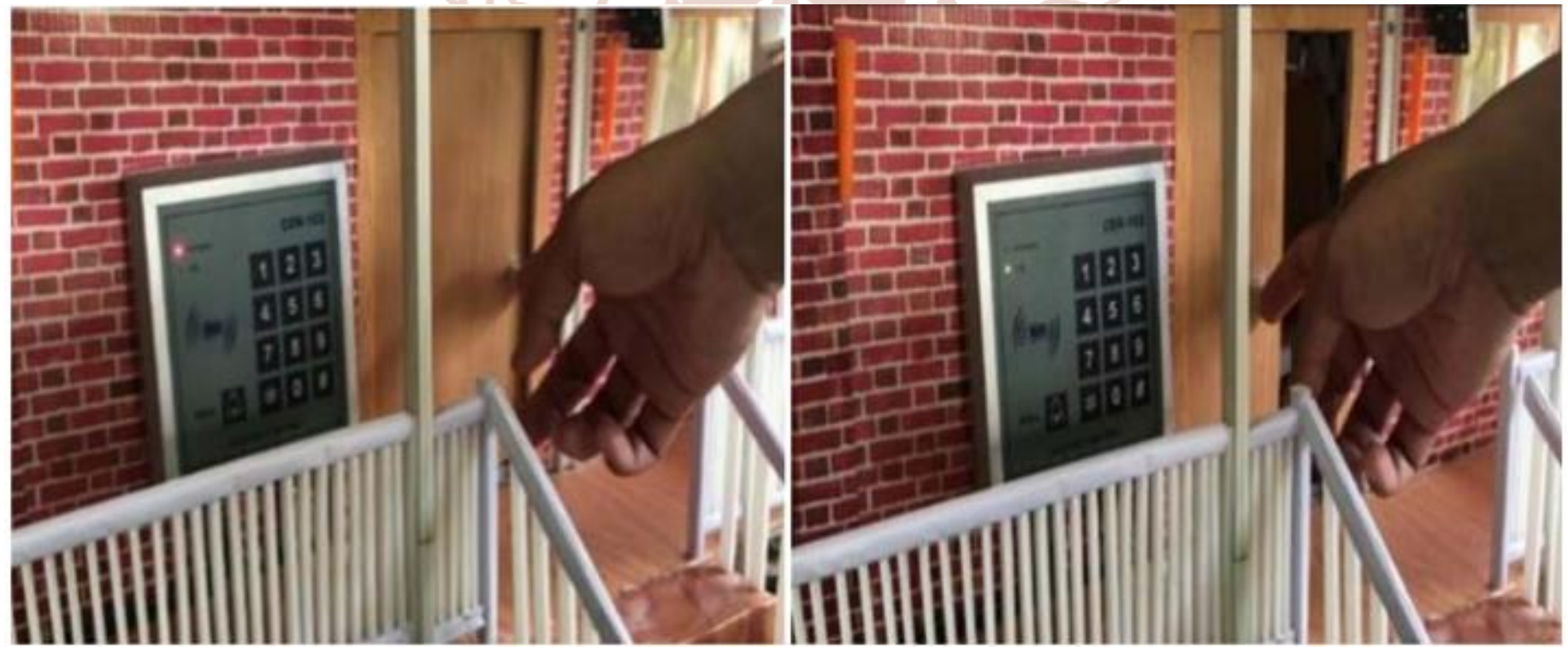

Figure14. Test and Result of Main Door Access Control System 


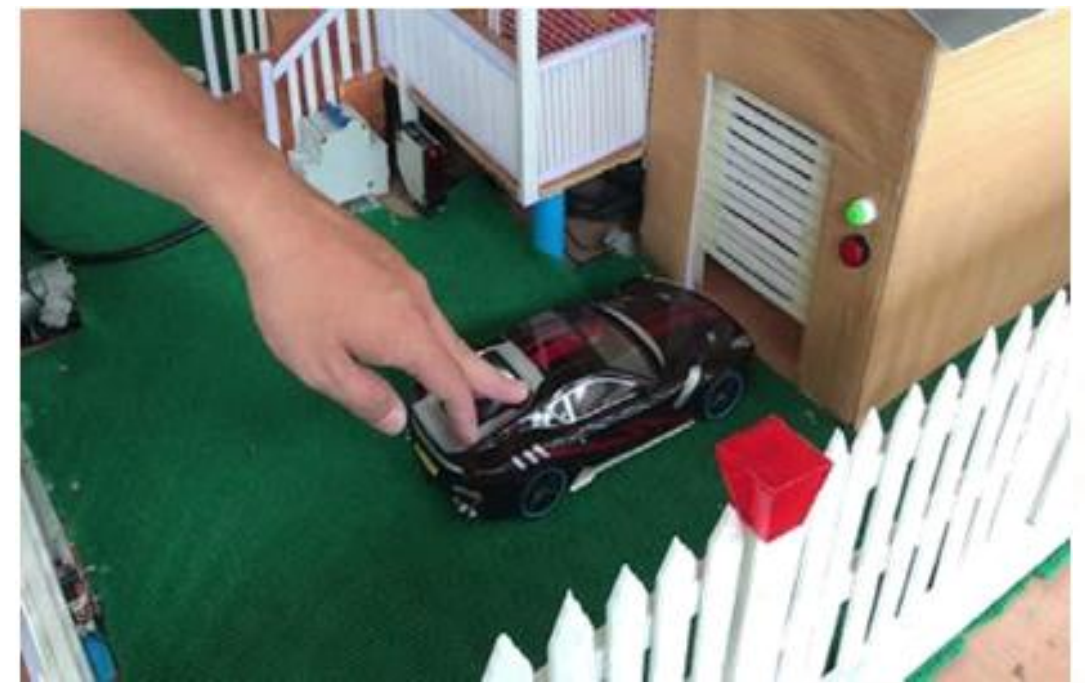

Figure15. Test and Result of Garage Control System

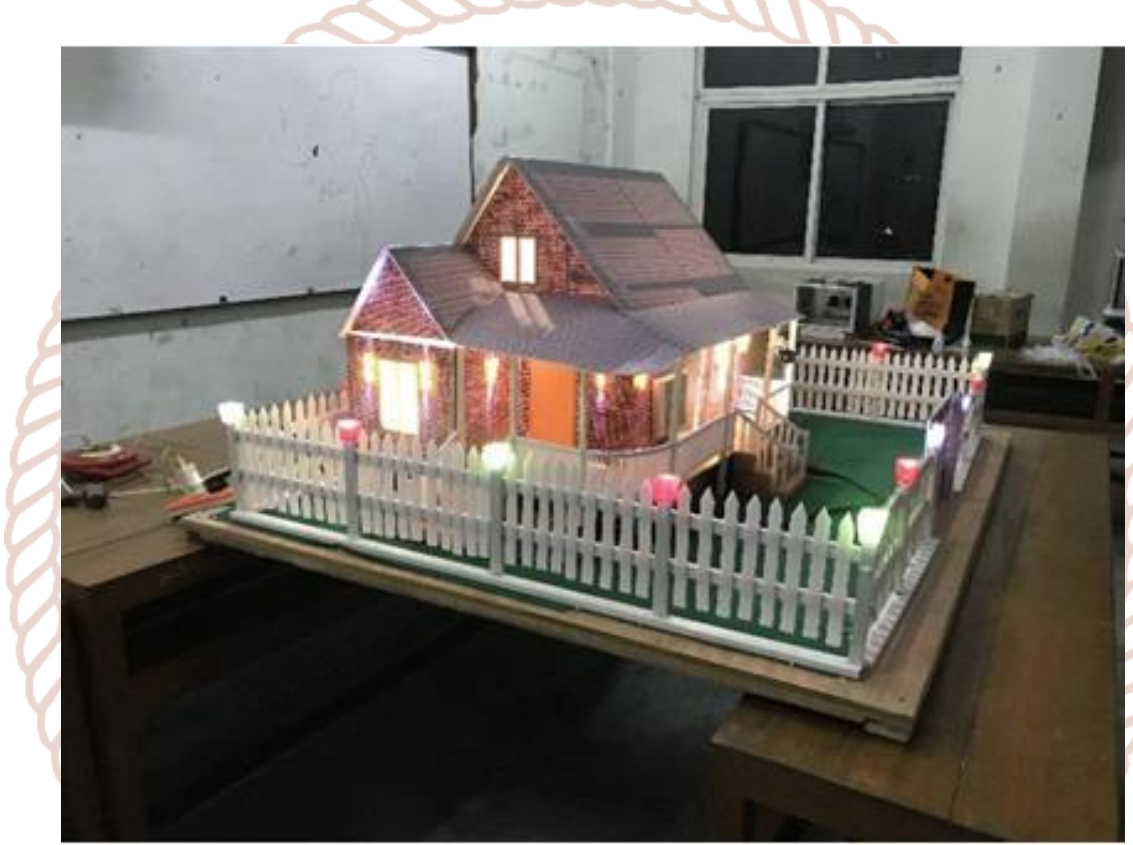

Figure16. Final Test and Result of Overall Smart Home System

\section{CONCLUSION}

The main aim of this process is to apply PLC to design Home Automation system and all objectives in this research are successfully done as planned. Finally, the basic control system and logic design application can be used as a reference to design other applications of automation system. The smart home system has been successfully designed and simulated using Kinco Builder software. The home automation is designed with gate door control, CCTV, access control unlock system, fire alarm system, auto lighting control system and garage door control system.

\section{REFERENCES}

1. Kinco K5 Software and Instruction Manual, Kinco Automation (Shanghai) Ltd, web.kinco.cn/html/en/products/PLC/K5PLC/2013 08/092229.html

2. Introduction to Programmable Logic Controller, Astro Automation Co., Ltd.

3. Bolten, W: Programmable Logic Controller, Fifth Edition

4. Home Automation Using PLC, International Journal of Advanced Research in Electrical, Electronics and Instrumentation Engineering (IJAREEIE) Volume 5, Special Issue1, March 2016 